\title{
Complete Atrioventricular Septal Defect: Two-Patch Techniques and Modified Single Patch, Application-Outcomes.
}

\author{
Ahmet Arslan ${ }^{1}$, Sibel Ay ${ }^{1}$, Tamer Aksoy ${ }^{1}$, Ayşegül Karahan Zor ${ }^{1}$, Fatma Bahceci ${ }^{1}$, Resmiye

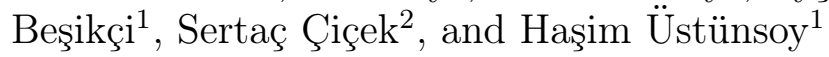 \\ ${ }^{1}$ Anadolu Medical Center \\ ${ }^{2}$ West Virginia University Children's Hospital
}

March 13, 2021

\begin{abstract}
Abstract The life expectancy and quality of patients with complete atrioventricular septal defect (CAVSD), which has undergone significant modifications in surgical correction since its definition, are increasing. Materials and Methods A total of 56 patients with a median age of 9 months were operated in the last 10 years. The modified single-patch (MSP) and two-patch technique (TPT) were applied to 37 patients and 19 patients, respectively. The patients were compared in terms of the ventricular septal defect (VSD) diameter, cardio pulmoner bypass (CPB) and aortic cross-clamp (ACC) time, intubation time, length of intensive care unit (ICU) in addition to demographic and hospital data. Long term results of 45 patients have been evaluated for 73,2 $\pm 4,06$ months meanly. Results It was observed that the age distribution of the patients who underwent MSP was lower $(\mathrm{p}=0.003)$, and were more female patients $(\mathrm{p}=0.023)$. The VSD diameter was larger in the TPT $(\mathrm{p}=0.000)$. The right atrioventricular valve (RAVV) repair was observed significantly more in the MSP technique $(\mathrm{p}=0.043)$. CPB and ACC time were found to be significantly longer in the TPT technique according to the T-test result. While postoperative LAVV regurgitation was found to be lower in the MSP $(\mathrm{p}=0.016)$, the amount of drainage was higher in the TPT. No statistical significance was detected in other comparative values of early and the long term results of the both tecniques. Conclusion In this retrospective study, it was observed that the MSP was advantageous in surgical outcomes, its easier applicability in accordance with the literature.
\end{abstract}

\section{Complete Atrioventricular Septal Defect: Two-Patch Techniques and}

Modified Single Patch, application-outcomes.

Ahmet Hulisi Aslan ${ }^{1}$, Sibel Ay², Tamer Aksoy², Ayşegül Karahan Zor ${ }^{3}$,

Fatma Bahçeci ${ }^{1}$, Resmiye Töre Beşikci ${ }^{4}$, Sertaç Çicek ${ }^{5}$, Haşim Üstünsoy ${ }^{1}$

${ }^{1}$ MD, Department of Cardiovascular Surgery, Anadolu Medical Center, Gebze, Kocaeli, TURKEY

${ }^{2}$ MD, Department of Cardiovascular Anesthesiology, Anadolu Medical Center, Gebze, Kocaeli, TURKEY

${ }^{3}$ MD, Department of Cardiology, Anadolu Medical Center, Gebze, Kocaeli, TURKEY

${ }^{4} M D$, Department of Pediatric Cardiology, Anadolu Medical Center, Gebze, Kocaeli, TURKEY

${ }^{5}$ MD, Department of Pediatric Cardiothoracic Surgery, West Virginia University Children's Hospital, Morgantown, USA

RUNNING TITLE: Complete Atrioventricular Septal Defect

${ }^{*}$ Corresponding author: 
Tamer AKSOY Phone: +90 2626785517 Mobile: +90 5327172237

Email Address: tamermd@hotmail.com Address: Anadolu Sağlık Merkezi Hastanesi, Kalp Sağlığı Bölümü, Cumhuriyet Mah. 2255 Sok. No:3 Çayırova Mevkii, 41400 Gebze, Kocaeli

Conflicts of Interest and Source of Funding :

This study was not funded by any institution or company and we declare no conflict of interest.

Data Availability Statement :

The data that support the findings of this study are openly available in [repository name e.g "figshare"] at http://doi.org/[doi], reference number [reference number].

\section{Abstract}

The life expectancy and quality of patients with complete atrioventricular septal defect (CAVSD), which has undergone significant modifications in surgical correction since its definition, are increasing.

\section{Materials and Methods}

A total of 56 patients with a median age of 9 months were operated in the last 10 years. The modified singlepatch (MSP) and two-patch technique (TPT) were applied to 37 patients and 19 patients, respectively. The patients were compared in terms of the ventricular septal defect (VSD) diameter, cardio pulmoner bypass (CPB) and aortic cross-clamp (ACC) time, intubation time, length of intensive care unit (ICU) in addition to demographic and hospital data. Long term results of 45 patients have been evaluated for $73,2 \pm 4,06$ months meanly.

\section{Results}

It was observed that the age distribution of the patients who underwent MSP was lower $(\mathrm{p}=0.003)$, and were more female patients $(\mathrm{p}=0.023)$. The VSD diameter was larger in the TPT $(\mathrm{p}=0.000)$. The right atrioventricular valve (RAVV) repair was observed significantly more in the MSP technique $(\mathrm{p}=0.043)$. $\mathrm{CPB}$ and ACC time were found to be significantly longer in the TPT technique according to the T-test result. While postoperative LAVV regurgitation was found to be lower in the MSP $(\mathrm{p}=0.016)$, the amount of drainage was higher in the TPT. No statistical significance was detected in other comparative values of early and the long term results of the both tecniques.

\section{Conclusion}

In this retrospective study, it was observed that the MSP was advantageous in surgical outcomes, its easier applicability in accordance with the literature.

Key words: Congenital heart surgery,complete atrioventricular septal defect

\section{Introduction}

This study was conducted with the permission of the local ethics committee. Complete atrioventricular septal defect was defined by Lillhei et al. in $1955 .{ }^{1-2}$ It constitutes 3 to $4 \%$ of all congenital cardiac defects, and insidance of 2-3 per thousand live births. ${ }^{3}$ It is observed most often with Down syndrome (25-71\%) and is more common in females. $\mathrm{S} / \mathrm{M}=1.3 / 1$. Surgical morbidity and mortality, which were high in the early periods, have come to the present day by being improved with a better understanding of congenital surgical anatomy, success in the treatment of pulmonary hypertension, surgical techniques, and the guidance of technological developments. ${ }^{6,7,8}$ Almost all cases can be operated with good outcomes in the early stages of the disease. ${ }^{9}$

Complete correction surgery, which started with the use of the TPT by Trusler in 1975, has now evolved into a surgery that tends to not use patches for VSD closure with the MSP technique of Ben Wilcox and Graham Nunn. $3,8,10,11$ Along with all these, ideal surgical timing, optimal treatment strategy (primary or staged surgery), single - two-patch techniques are still controversial. 


\section{Materials and Methods}

A total of 56 patients; 33 females (60\%), 23 males (40\%) were operated for CAVSD in our clinic between 2009 and 2019. The demographic and surgical data of the patients with a median age of $18.19 \pm 29,9$ months (2-180), the male and female numbers with ratios of 33 males (60\%) and 23 females (40\%), and the mean weight of $9.87 \pm 7.96 \mathrm{~kg}(3.3-41)$ are summarized in Table 1.

In preoperative echocardiography, 46 patients were determined to be Rastelli type A (82,2\%), 7 patients were type B $(12,5 \%), 3$ patients were type C ( 5,3\%). The mean VSD diameter was found to be $10.23 \pm$ $4.47 \mathrm{~mm}(3-23)$. Preoperative LAVV regurgitation was determined to be moderate and severe in 28 and 9 patients, respectively while right AV valve regurgitation was also found in 24 and 9 patients, respectively. There was a mitral cleft in all patients. There was no preoperative left ventricular outflow truck obstruction (LVOTO) in any of our patients.

Additional anomalies are presented in Table 2.

Before total correction, 2 patients underwent BT shunt surgery, and 6 patients underwent pulmonary banding in the other centers.

As surgical techniques, cannulation of the ascending aorta after standard median sternotomy, bicaval venous cannulation, and moderate hypothermia were applied, and antegrade blood cardioplegia was used. The MSP technique was applied to 37 (66\%) patients, and the TPT was applied to 19 (34\%) patients. Mitral cleft repair was performed in all patients. Additional valve repair was performed on the left atrioventricular valve (LAVV) in 16 patients and the right atrioventricular valve (RAVV) in 16 patients. The conventional single-patch technique was not used in any of our patients.

Both patient groups were compared in terms of age groups, male-to-female ratio, VSD diameter, CPB and aortic ACC time, intubation time, length of ICU and hospital stay, drainage level, blood product usage amounts, mortality and morbidities such as postoperative left and right valve regurgitation, heart failure, infection, chylothorax, and cerebrovascular events.

The long-term results of the study were evaluated over 45 patients who could be followed up for $73,2+4,06$ (22-128) months meanly.

\section{Statistical Analysis}

SPSS Windows version 21 was used for the statistical evaluation of the data. Numerical values were presented as mean +- standard deviation or median (lowest-highest) according to their compatibility with a normal distribution. Categorical variables were expressed in numbers and total percentages. For numerical data, in the comparison of two groups, the independent samples t-test was used for normally distributed data, the Mann-Whitney U test was used for non-normally distributed data, and the chi-square test was used for categorical variables. For statistical significance, the p-value was accepted to be $<0.05$.

\section{Results}

The mean CPB time was $98+-31$ minutes (34-175), and the ACC time was 70.13 +- 25 minutes (89140). While the mean drainage amount was $427+-409 \mathrm{ml}$ (10-2200), the blood product amount used was $597.41+-444.36 \mathrm{ml}(0-2750)$.

The number of moderate and severe postoperative LAVV regurgitation was determined to be 15 and 1 , respectively, and right atrio-ventricular (AV) valve regurgitation was found to be 10 and 0 , respectively.VSD creating a slightly shunt was observed in one postoperative patient.

The mean intubation time was $75.09+-108.47$ hours $(4-456)$, the length of intensive care stay was 7.82 +- 7.46 days (1-31), and the total length of hospital stay was 17.14+-15.63 days (4-90).

(Table 3) 
Of 7 patients with rhythm problems, 4 patients (7.1\%) had complete AV block, 2 (3.5\%) had Junction Ectopic Tachycardia (JET), and 1 patient had Right Bundle Branch Block (RBBB).

A permanent pacemaker was implanted in patients with complete block.

While two patients were treated for tamponade and 4 patients for chylothorax, a pericardial tube was placed in 1 patient remaining in the long term with a diagnosis of Dressler's syndrome and a peritoneal dialysis catheter was inserted in 8 patients. Twelve patients used long-term antibiotherapy due to postoperative pneumonia and 2 patients due to urinary infection. One patient was treated with the diagnosis of sepsis, and one patient was treated with the diagnosis of an epileptic attack. $\mathrm{NO}_{2}$ inhalation therapy was applied to 4 patients due to high pulmonary pressure. (Table 4 )

While the median of age of patients who underwent MSP was 7,5 months, the distribution of patients who underwent TPT was concentrated over 14 months $(\mathrm{p}=0.003)$. In the comparison of females and males in both groups, it was observed that there were significantly more female patients in the MSP group $(\mathrm{p}=0.023)$. When the VSD diameter between both techniques was compared by the Mann-Whitney U test, the mean rank was observed to be $8,2 \mathrm{~mm}$ in MSP and $13,78 \mathrm{~mm}$ in TPT $(\mathrm{p}=0.000)$ (Graph 1$)$. While there was no difference between left atrioventricular valve repair, the right atrioventricular valve repair was observed to be significantly more $(p=0.043)$ in the MSP technique.

When CPB time was compared, according to the independent samples t-test result, the mean and standard deviation was 125.3 and 27.3 respectively in TPT, and the mean and standard deviation was found to be 83.4 and 23.8, respectively in MSP (Graph 2). Likewise, ACC time was compared, and mean and standard deviation was determined to be 88.6 and 23.5 respectively in TPT, and 60.1 and 22.3 respectively in MSP (Graph 3). According to these results, both CPB and ACC time was significantly longer in the TPT.

The comparison of postoperative LAVV regurgitation was performed with the chi-square test, and the moderate-severe group was observed statistically significantly less in the MSP technique $(\mathrm{p}=0.016)$. The amount of drainage was compared by the Mann-Whitney U test, and the mean rank and arithmetic mean were found to be 36.5 and 603 respectively in TPT, and 23.5 and 334 respectively in MSP. These values make the excessive amount of drainage in TPT statistically significant. Statistical significance was not determined in other comparative values.

Hospital mortality was $2(3.5 \%)$. A patient with Down syndrome who underwent CAVSD repair with a MSP and both left and right AV valve repair died due to aspiration pneumonia in the early period after discharge. The second patient had multiple muscular VSDs and was previously palliated with pulmonary banding due to high pulmonary pressure. The patient, who needed a permanent postoperative pacemaker following repair with the TPT, died due to respiratory failure in intensive care follow-ups.

In terms of the long term (mean:73 months) results of these patients; early mortality within 22 months was $4.4 \%$ with 2 patients and late mortality was $6.6 \%$ with 3 patients. Overall mortality rate was $11.1 \%$. Three among the five patients who died, had been operated using TPT and the other two with MSP. Two patients died due to non-cardiac causes whereas we lost our 3 patients from cardiac causes. One patient who died due to cardiac reasons had permanent pacemaker and sudden death was reported due to rhythm disturbance. One of the other two patients was lost in our center and the other one in an external center after reoperation which was made due to LAVV insufficiency. Overall survival was determined as 89,9 for 73 monhts. While early reoperation was not performed after discharge, 3 patients $(6.6 \%)$ were reoperated in the late period due to LAVV insufficiency. Two of these patients were operated in our center within five years, one was operated at a later period in the other center. Five-year survival without reoperation was $95.6 \%$ and ten-years survival was $93.4 \%$. MSP was applied to one patient who underwent reoperation and the other two patients with TPT. There was no statistical difference in long term term result of the both tecniques.

\section{Discussion}

Since the classification of Rastelli, CAVSD is a congenital anomaly, the anatomy of which is well known 
and operated with very successful outcomes with the contribution of developing technology and surgical techniques. Coexisting additional anomalies do not affect the outcomes with low morbidity and mortality. Andrew et al. stated that there was no difference between a single patch or a two-patch in terms of residual lesion or valve regurgitation in trisomy 21 cases. ${ }^{12}$ Ixe et al. reported the optimal surgical time as 3-6 months in among their patients to who have been operated $92 \%$ by TPT and $2.2 \%$ the single-patch technique. Besides they have observed that Down syndrome was not a risk factor for reoperation. ${ }^{13}$ On the other hand, Tumanyan at al compared 214 patients with only CAVSD to 163 patients with concomitant Down syndrome. They have applied the TPT to $75.4 \%$ and the single-patch technique to $24.6 \%$. Although the researcher could not find a difference in terms of the repair technique, he stated that the additional morbidity of Down syndrome patients compared to patients without this accompanying disorder, affected the recovery period and life expectancy. ${ }^{14}$ In our cases, as can be seen from the table, the coexistence of additional cardiac anomalies and Down syndrome $(65 \%)$ is quite common. However, like other anomalies, trisomy 21 did not cause additional morbidity and mortality, which revealed statistical significance.

CAVSD malformations are patients with AV junction defect and a common single complete AV valve. ${ }^{15-16}$ In CAVSD, the increased flow due to a large defect may increase pulmonary pressure very early. ${ }^{1}$ This does not cause problems due to high pulmonary resistance in the first 3 months. Full correction surgery in the early period prevents pulmonary vascular disease. In this sense, CAVSD repair should be performed in an average of 4 months. Bakhtiari and Rudid Takacs reported an operation time in the 3.8 months on average in their series. ${ }^{17}$ In our series, the fact that there were $23(\% 41)$ patients who have right ventricle outflow truct stenosis and pulmonary banding due to additional anomalies. Mean and median age of these patients are 17 and 33 months respectively. Nevertheless, almost all of our patients came from abroad and from regions where early diagnosis-treatment remained insufficient caused the our median operation timing to be the 7,5 months in MSP and the 14 months in TPT, and the mean average was the 9 months. However, there were no serious problems related to pulmonary hypertension, and just 4 of 6 patients who had undergone pulmonary banding before required $\mathrm{NO}_{2}$ inhalation.

Transthoracic echocardiography or even perinatal echocardiography is sufficient for diagnosis. Cohen GA reported that intraoperative transesophageal echocardiography (TEE) would be highly an instructive guiding and beneficial examination during CAVSD repair as in all congenital heart disease surgeries. ${ }^{18}$ Approximately $35 \%$ of our cases were performed under guidance of intraoperative TEE. Cardiac catheterization, magnetic resonance imaging, and computerized tomography should be performed at an advanced age to measure pulmonary pressure reversibility or if evaluation for additional anomaly is required.

The MSP has been used more frequently in the last decade, in addition to the conventional single-patch and TPT that have been used in the past. ${ }^{8}$

In this retrospective study, $66 \%$ of the cases were operated with MSP technique, while $34 \%$ were operated with the TPT. The conventional single-patch technique was not preferred in our center like in many centers. In our series, the VSD diameter was found to be smaller and ACC and CPB times were found to be shorter in the MSP technique. Li et al. compared the MSP and TPT in terms of many parameters (VSD diameter, CPB-ACC time, mortality, reoperation). As in our series, the VSD diameter was smaller and the CBP and ACC times were shorter in MSP, and there was no significant difference in other parameters. ${ }^{(19)}$ Jeong IS and Pan G found only CPB and ACC time and hence ischemia time shorter in the use of a modified single patch, while they found other parameters to be similar. ${ }^{20-21}$

In the study, short CPB and ACC time did not create a significant difference in the intubation time, duration of intensive care and hospitalization, in accordance with the literature. Moreover, the amount of drainage was significantly higher in TPT, but there was no significant difference in the use of blood products. This is also compatible with our institutional policy that we use restricted blood-blood products for drainages not causing clinical and hemodynamic deteriotaion. ${ }^{22}$

The late outcomes of the both tecniques were analysed in the literature, there was no statistically significant difference. ${ }^{23}$ The most important factor affecting the late period outcomes is the incidence of reoperations. 
Ginde S et al. followed 198 patients for an average of 17.2 years and found LAVV regurgitation as the most common cause of reoperation. In this series, the 30 -year no-reoperation rate is $78 \%$, while the 10 -year rate is $88 \% .{ }^{24}$ Prifti and Massimo stated that left LAVV malfunctions during the primary repair of CAVSD were important risk factor for reoperations. ${ }^{25}$ In our study where we compared TPT and MSP, performed mostly, moderate-severe LAVV regurgitation was observed statistically significantly less in the MSP group in the postoperative early and middle period. The reduced three-dimensional calculations in the MSP technique, the number of patches and the easy applicability of the technique cause this result. Graham Nunn reported $1.6 \%$ mortality and $2.3 \%$ residual VSD in 128 patients in whom he applied MSP in his series, while he did not report valve regurgitation in these patients. In the mean time he observed late-stage LAVV regurgitation to be $0 \%$ and LVOTO to be $2.3 \%$ in 46 patients to whom he applied a two-patch. ${ }^{8}$ LVOTO was not observed in any of our groups.

When the two techniques are compared conventionally, reoperation rates emerge as the most important difference. LVOTO is not observed in the MSP, whereas reoperation rates can increase up to $15 \%$ due to LVOTO in the TPT. Mortality rates are $1.2 \%$ in the MSP and 3.5\% in the TPT. Reoperation rates due to the $\mathrm{AV}$ valve are $2.2 \%$ and $7.2 \%$, and pacemaker rates are $0.4 \%$ and $1.9 \%$, respectively. ${ }^{26-27} \mathrm{In}$ our series, while there was no difference in terms of mortality and pacemaker implantation, our overall pacemaker average was observed to be above the average indicated in the literature (4\%). While the AV block risk was 2-2.5\% in general in the TPT, it is between 0-1\% in many series in which the MSP is applied. ${ }^{26}$

The most common cause of reoperation after additional AV valve repair is recurrent LAVV regurgitation $(9-17 \%){ }^{28-29}$ However, as can be seen from the above-mentioned rates, the reoperation rates (2.2\%) are quite low in the MSP. Some studies have stated that the most important cause of left ventricular AV valve regurgitation is annular dilatation, which is related to the operation timing. ${ }^{30-31}$ In addition to its ease to perform between 2-4 months, reduces reoperation rates. Delayed surgical timing and LAVV insufficiency are regarded as important risk factors for reoperation. ${ }^{13}$ Although LAVV insuffiency as a cause of reoparation was more frequent in our series, both could not be identified as a risk factors in our study. However, this result may have been obtained with the positive effect of the MSP technique applied at a high rate of $66 \%$ on LAVV insufficiency in our series. Alhough our patients operation timing was later that the recommended time in the literature, no difference was found in long terms of reoperation and mortality when the two techniques were compared.

The most significant advantage of the MSP technique is eliminating complications that may occur due to the dimensions of this patch by not placing a VSD patch. The non-splitting of the valve prevents tissue loss from the valves, thus eliminating another technical cause that may contribute to AV valve regurgitation. The mortality in reoperations due to left AV valve residual defect and other reoperation causes is about $9.8 \% .{ }^{26}$ The rate of LVOTO is usually $4.2 \%$. While Geoffrion et al. presented this rate as $0.6 \%$ in their series, the rate was reported to be $0 \%$ in Nunn's series in the MSP technique. ${ }^{26-27}$

In conclusion, when the modified single-patch technique is compared with the two-patch technique in this series, the CPB-ACC time is shorter in favor of MSP, the VSD is smaller in accordance with the nature of the technique, LAVV regurgitation is less, and, accordingly, the risk of AV valve reoperation is lower. Therefore MSP technique may be prefeferred in patients with suitable VSD diameter and localization in CAVSD.

\section{References:}

1. Lev M: The architecture of conduction system in congenital heart disease. I. Common atrioventricular orifice, AMA Arch Pathol 65:174, 1958

2. Gerbode F: Surgical repair of endocardial cushion defect, Ann Chir Thorac Cardiovasc 1: 753, 1962.

3. Backer CL, Mavroudis C: Atrioventricular Canal Defects. In Mavroudis C, Backer CL, eds: Pediatric Cardiac Surgery, Philadelphia, Mosby, 2003.

4. Mitchell SC, Korones SB, Berendes HW: Congenital heart disease in 56,109 live births. Incidence and natural history, Circulation 43:323, 1971.

5. Spicer RL: Cardiovascular disease in Down syndrome, Pediatr Clin North Am 31: 1331,1984 
6. Rastelli G, Kirklin JW, Titus JL: Anatomic observations on complete form of persistent common atrioventricular canal with special reference to atrioventricular valves, Mayo Clin Proc 41:296, 1966.

7. Trachte AL, Lobato EB, Urdenata F, Hess PJ, Klodell CT, Martin TD, Staples ED, Beaver TM. Oral sildenafil reduces pulmonary hypertension after cardiac surgery. Ann Thorac Surg. 79;194-197, 2005.

8. Nunn GR, Atioventricular Canal: Modified Single Patch Technique. Pediatric Cardiac Surgery Annual 10: 28-31 2007.

9. Kobayashi M, Takahashi Y, Ando M: Ideal timing of surgical repair of isolated complete atrioventricular septal defect, Interact Cardiovasc Thorac Surg 6(1):24-6, 2007.

10. Trusler GA: Discussion of Mills NL, Ochsner JL, King TD: Correction of type C complete atrioventricular canal. Surgical considerations, J Thoracic Cardiovasc Surg 71:20, 1976.

11. Meskishvili VA, İshino K, Dahnert I, Uhlemann F, Yuguo W, et al. Correction of complete atrioventricular septal defects with the double-patch technique and cleft closure. Ann Thorac Surg 62:519-25, 1996.

12. Atz AM, Hawkins JA, Lu M, Cohen MS, et al. Surgical management of complete atrioventricular septal defect: Associations with surgical technique, age, and trisomy 21. J Thoracic and cardiovasc Surg. 141:6, 1371-9, 2011.

13. Xie O, Brizard CP, d'Udekem Y, Galati JC, et al. Outcomes of repair of complete atrioventricular septal defect in the current era. European Journal of cardio-thoracic surgery. 45:610-17, 2014.

14. Tumanyan MR, Filaretova OV, Chechneva VV, Gulasaryan RS. Repair of Complete Atrioventricular Septal Defect in infants with Down Syndrome: Outcomes and Long-Term Results. Pediatr Cardiol, 36: 71-75. 2015.

15. Pencoske PA, Neches WH, Anderson RH, Zuberbuhler JR. Further observations on the morphology of atrioventricular septal defects. J Thorac Cardiovasc Surg. 90: 611-622 1985.

16. Anderson RH, Ho SY, Falcao S, Daliento L, Rigby ML. The diagnosis features of atrioventricular septal defect with common atrioventricular junction. Cardiol Yaung. 8:33-49. 1998.

17. Bakhtiary F, Takacs J, Cho MY, Razek V, et. Al. Long-term Results after repair of complete atrioventricular Septal Defect with two-patch technique. Ann Thorac Surg. 89:1239-43, 2010.

18. Cohen GA, Stevenson JG. Intraoperative Echocardiography for Atrioventricular Canal: DecisionMaking for Surgeons. Pediatr Card Surg Ann. 10:47-50, 2007.

19. Li D, Fan Q, Iwase T, Hirata Y. Modified single-patch technique versus two-patch technique for the repair of complete atrioventricular septal defect: A meta-analysis. Pediatr Cardiol. 38:1456-64, 2017

20. Jeong IS, Lee CH, Lee C, Lim HG et al. Surgical outcomes of the modified single patch technique in complete atrioventricular septal defect. Interactive Cardiovasc and Thoracic Surg. 8:435438, 2009.

21. Pan G, Song L, Zhou X, Zhao J. Complete atrioventricular septal defect: Comparison of modified single-patch technique with two-patch technique in infants. J Card Surg. 29:251-55, 2014.

22. Tempe DK, Khurana P. Optimal Blood Transfusion Practice in Cardiac Surgery. J of Cardiothoracic and Vascular Anesthesia. 2018; 32(6): 2743-45.

23. Senaidi KS, Ross DB, Rebeyka IM, Harder J, et al. Comparison of two surgical technique for complete atrioventricular septal defect repair using two and three-dimensional echocardiography. Pediatr Cardiol. 35:393-398, 2014.

24. Ginde S, Lam J, Garick DH, Cohen S et al. Long term outcomes after surgical repair of complete atrioventricular defect. J thorac Cardiovasc Surg 150:369-74, 2015.

25. Prifti E, Bonacchi M, Baboci A, Giunti G. Surgical outcome of reoperation due to left atrioventricular valve regurgitation after previous correction of complete atrioventricular septal defect. J. Card Surg 28:756-63, 2013.

26. Geoffrion TR, Singappuli K, Murala JS. A review of the Nunn modified single patch technique for atrioventricular septal defect repair. Translational Pediatrics 2018; 7(2) 1-14.

27. Backer CL, Eltayep O, Monge MC, et al. No ventricular Septal Defect patch Atrioventricular septal defect repair. Oper Tech. Thorac Cardiovascular Surg. 2015;20:279-92.

28. Draguescu A, Fouilloux V, Ghez O, et al. Complete atrioventricular canal repair under 1 year: Rastelli one-patch procedure yields excellent long term results. Ann Thorac Surg 2008; 86: 1599-604. 
29. Prifti E, Bonacchi M, Bernabei M, et al. Repair of Complete Atrioventricular Septal Defect with tetralogy of Fallot. J. Card. Surg 2004; 19:175-83.

30. Salihoğlu E, Özkan S, Özçobanoğlu S, et al. Preliminary results of direct closure of an atrioventricular septal defect: revisiting the original technique. Turk J Thorac Cardiovasc Surg 2012;20:699-704.

31. Li D, Fan Q, IwaseT, et al. Modified Single Patch Technique versus Two patch Technique for the repair of complete Atrioventricular Septal Defect: A Meta-Analysis Pediatr Cardiol 2017;38: 1456-64

\begin{tabular}{lllll}
\hline Demographic Data & & MSP & MSP & TPT \\
\hline Median Age (Months) & & 7,5 & 7,5 & 14 \\
Sex & & $19 \mathrm{M}, 18 \mathrm{~F}$ & $19 \mathrm{M}, 18 \mathrm{~F}$ & $14 \mathrm{M}, 5 \mathrm{~F}$ \\
Weight & & $9.26 \pm 8.74$ & $9.26 \pm 8.74$ & $11.2 \pm 6.59$ \\
Down Syndrome & $26(70 \%)$ & $26(70 \%)$ & $11(64 \%)$ \\
NYHA Class I Class II Class III & & 2872 & 2872 & $172-$ \\
RASTELLI & RASTELLI & & 3016 & 3016 \\
Type A & Type A & & 52 & 52 \\
Type B & Type B & 21 & 21 \\
Type C & Type C & $8,213,78$ & $8,213,78$ \\
Mean VSD diameter & Mean VSD diameter & & 2017 & 2017 \\
Preop LAVVR & Preop LAVVR & & 1815 & 1815 \\
Preop RAVVR & Preop RAVVR & & & \\
\hline
\end{tabular}

Table 1: Demographic Data

\section{Abbreviations:}

LAVVR:Left atrioventricular valve regurgitation

NYHA:New York Heart Association

RAVVR:Right atrioventricular valve regurgitation

VSD:Ventricular septal defect,

\begin{tabular}{lll}
\hline Additional anomalies & MSP & TPT \\
\hline ASD +PDA & 15 & 3 \\
PDA & 8 & 2 \\
Pulmonary stenosis & 4 & 3 \\
Operation pulmonary banding & 2 & 4 \\
TOF & 1 & 4 \\
DORV + PS & - & 3 \\
ASD & 1 & 1 \\
Operated BT shunt & - & 2 \\
RV hypoplasia & 1 & 1 \\
PAPVC + mesocardia + LPSVC & - & 1 \\
Mesocardia & 1 & - \\
Multiple VSD & - & 1 \\
LPSVC+PDA: & 1 & - \\
\hline
\end{tabular}

Table 2: Additional anomalies

\section{Abbreviations:}


ASD:Atrial septal defect

BT:Blalock Taussig

DORV:Double Outlet Right Ventricle

LPSVC:Left Persistent Superior Vena Cava

PAPVC:Partial Abnormal Pulmonary Venous Connection

PDA:Patent Ductus Arteriosus

PS: Pulmonary Stenosis

RV:Right Ventricle

TOF:Tetralogy of Fallot

\begin{tabular}{lll}
\hline & MSP & TPT \\
\hline CPB time & $93.97 \pm 23.65 \mathrm{~min}$ & $125.31 \pm 27.29 \mathrm{~min}$ \\
ACC & $60.62 \pm 22.17 \mathrm{~min}$ & $88.63 \pm 23.53 \mathrm{~min}$ \\
Intubation time & $78.02 \pm 117.76 \mathrm{~h}$ & $69.36 \pm 93.88 \mathrm{~h}$ \\
Length of intensive care stay & $7.59 \pm 7.64$ & $8.26 \pm 7.47$ \\
Length of hospital stay & $15.91 \pm 2.71$ & $19.52 \pm 3.27$ \\
Drainage amount & $334.16 \pm 320.31$ & $603.15 \pm 511.72$ \\
Blood product & $505.54 \pm 286$ & $776.31 \pm 631.43$ \\
AV block & 2 & 2 \\
JET & 2 & - \\
RBBB & 1 & - \\
Pacemaker implantation & 2 & 2 \\
\hline
\end{tabular}

Table 3: Surgical Data

Abbreviations:

ACC:Aortic Cross-Clamp

$\mathrm{AV}$ :Atrioventricular

CPB:Cardio-Pulmonary Bypass

JET:Junction Ectopic Tachycardia

RBBB:Right Bundle Branch Block.

\begin{tabular}{lll}
\hline & MSP & TPT \\
\hline Pneumonia & 7 & 5 \\
UTI & 2 & - \\
Sepsis & - & 1 \\
Epileptic attack & - & 1 \\
Tamponade & 1 & 1 \\
Chylothorax & 1 & 3 \\
Advanced left AV valve regurgitation & 1 & - \\
Reintubation & 5 & 3 \\
Peritoneal dialysis catheter & 2 & 6 \\
Pericardial tube & 1 & -
\end{tabular}




\begin{tabular}{lll}
\hline & MSP & TPT \\
\hline NO inhalation & 2 & 2 \\
\hline
\end{tabular}

Table 4: Factors for Morbidity

Abbreviations:

NO: Nitric Oxyde

UTI: Urinary truct infection

\section{Graphs Legends}

Graph 1: Difference of VSD diameter

Graph 2: Comparasion of CPB time

Graph 3: Comparasion of ACC time

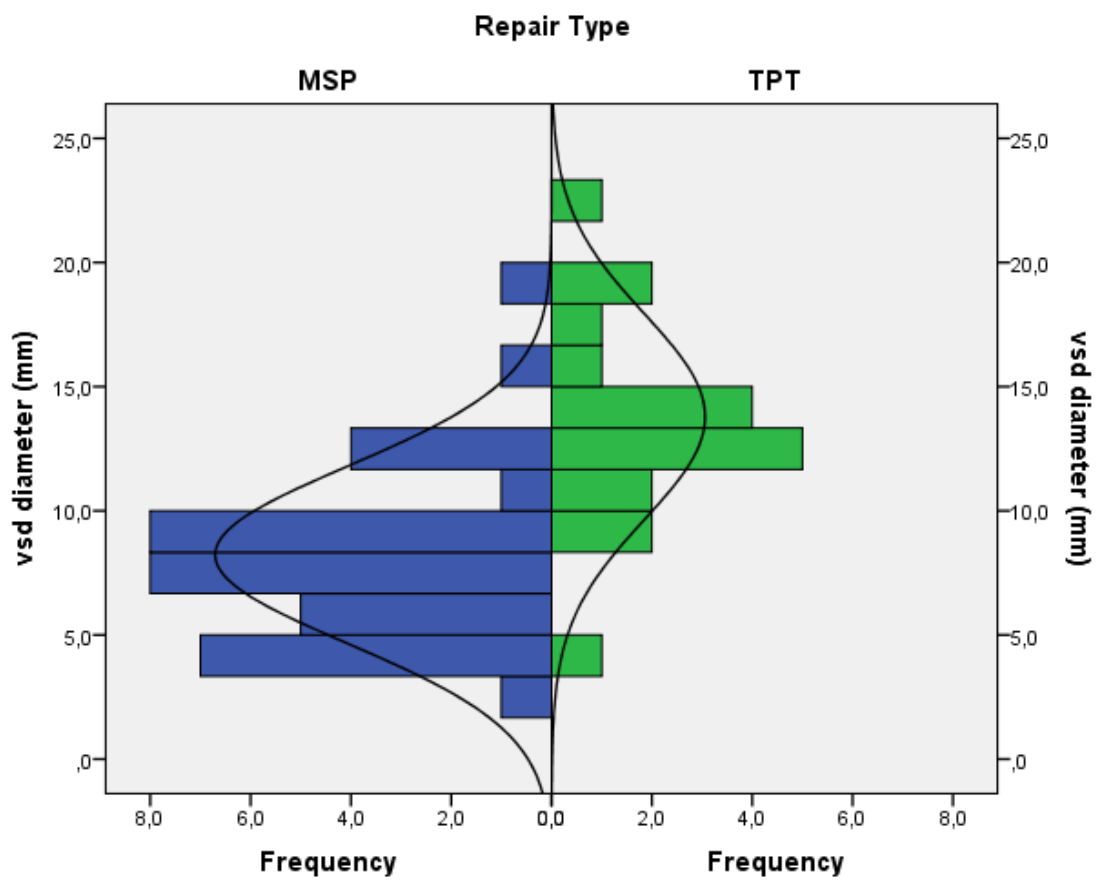

\section{Graph 1}




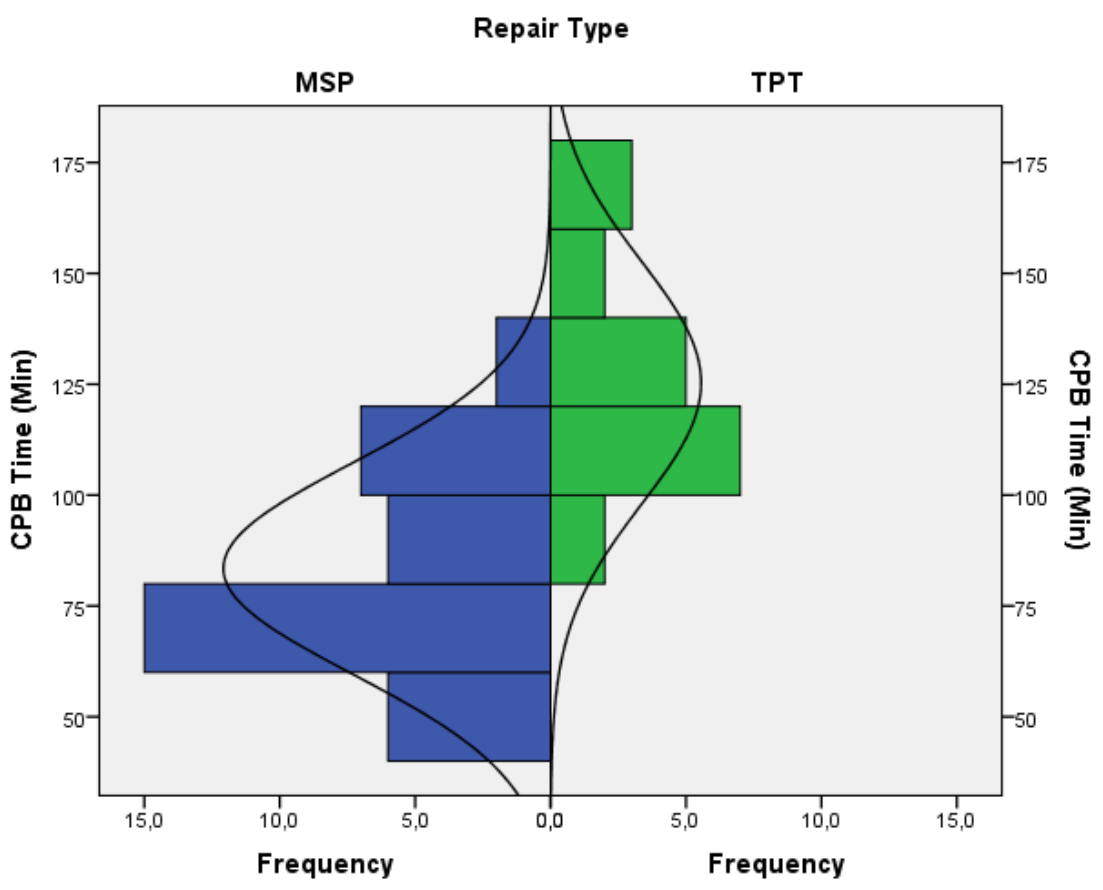

Graph 2

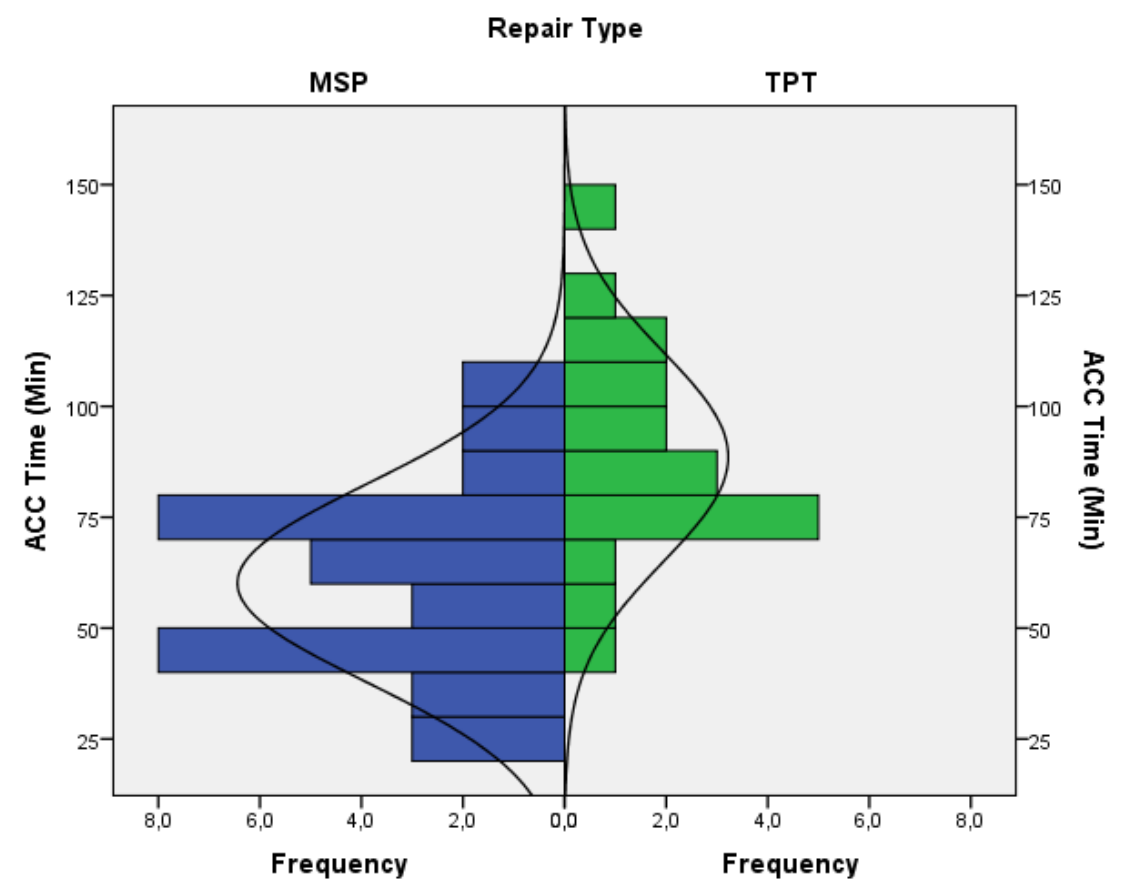

Graph 3

Hosted file 
Table 1.pdf available at https://authorea.com/users/401378/articles/513482-completeatrioventricular-septal-defect-two-patch-techniques-and-modified-single-patchapplication-outcomes

\section{Hosted file}

Table 2.pdf available at https://authorea.com/users/401378/articles/513482-completeatrioventricular-septal-defect-two-patch-techniques-and-modified-single-patchapplication-outcomes

\section{Hosted file}

Table 3.pdf available at https://authorea.com/users/401378/articles/513482-completeatrioventricular-septal-defect-two-patch-techniques-and-modified-single-patchapplication-outcomes

\section{Hosted file}

Table 4.pdf available at https://authorea.com/users/401378/articles/513482-completeatrioventricular-septal-defect-two-patch-techniques-and-modified-single-patchapplication-outcomes 


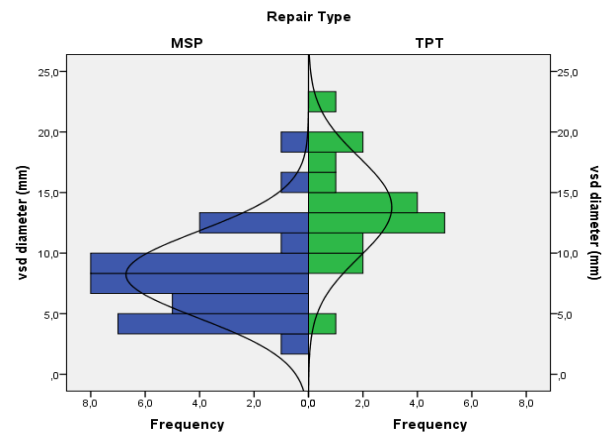




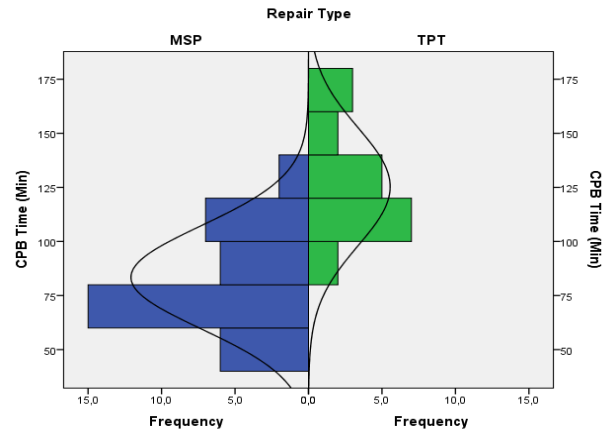




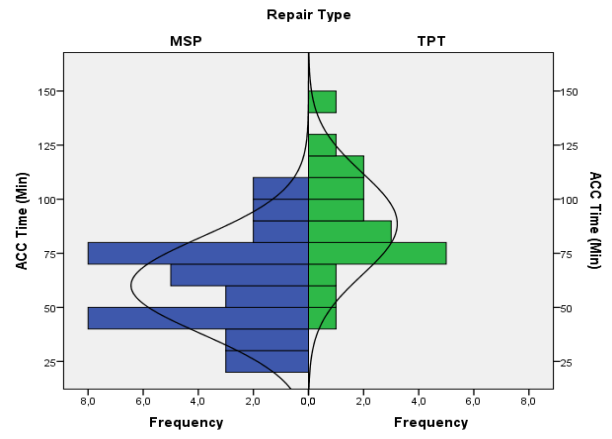

